Gut, 1979, 20, 848-853

\title{
Gilbert's syndrome: evidence of morphological heterogeneity
}

\author{
J. DAWSON ${ }^{1}$, D. L. CARR-LOCKE, I. C. TALBOT, AND F. D. ROSENTHAL \\ From the Department of Medicine, Royal Postgraduate Medical School, London, and Departments of \\ Medicine and Pathology, Leicester University Medical School, Leicester
}

SUMMARY Hepatic ultrastructure was examined by electron microscopy in 25 patients with Gilbert's syndrome and the changes in the smooth endoplasmic reticulum quantified by grid technique. Thirteen patients showed gross hypertrophy of the smooth endoplasmic reticulum (SER). These were designated Gilbert's EM Positive. The remaining 12, designated Gilbert's EM Negative, did not differ significantly from normal controls. The EM Positive group showed a significantly greater percentage response to caloric restriction $(\mathrm{P}<0.01)$ and an exaggerated response to nicotinic acid stimulation when compared with the EM Negative group and normal controls. These results suggest that SER hypertrophy is not, as previously suggested, a constant feature of Gilbert's syndrome but rather a characteristic of a distinct subpopulation.

Gilbert's syndrome is usually diagnosed when a patient is found to have an isolated unconjugated hyperbilirubinaemia in the absence of overt haemolysis (Arias, 1962). However, as a raised bilirubin alone can be a manifestation of more serious disease (Levine and Klatskin, 1964), various tests have been proposed in an attempt to provide a firm diagnosis of Gilbert's syndrome. McGee et al. (1975) found gross hypertrophy of the smooth endoplasmic reticulum in all nine of their patients with Gilbert's syndrome and suggested it to be of diagnostic value. The present study assesses this feature in a larger series and compares the results with two other proposed diagnostic tests; the bilirubin response to (1) caloric restriction (Owens and Sherlock, 1973; Felsher and Carpio, 1975), and (2) to nicotinic acid stimulation (Fromke and Miller, 1972; Davidson et al., 1975). The red cell half life was also determined, using radioactive chromium labelling, in view of the variable reports of shortened red cell survival in Gilbert's syndrome (Foulk et al., 1959; Powell et al., 1967; Berk et al., 1970).

${ }^{1}$ Present address and address for correspondence: Dr. J. Dawson, Division of Clinical Cell Biology, Clinical Research Centre, Northwick Park Hospital, Harrow, Middlesex.

Received for publication 6 June 1979

\section{Methods}

Twenty-five patients (age 14-52 years) with Gilbert's syndrome were studied; 20 males and five females. They were selected from consecutive patients who presented to general medical outpatients with a variety of non-specific symptoms and in whom the only abnormality found on investigation was an isolated, predominantly unconjugated, serum hyperbilirubinaemia (range 18 to $105 \mu \mathrm{mol} / \mathrm{l}$ ). All other tests of liver function, and cholecystography in those patients with vague abdominal symptoms, were normal. Extensive haematological tests excluded all common haemolytic diseases and the haemoglobin was normal in all cases.

A percutaneous liver biopsy was performed in all patients. A portion was immediately placed in ice cold Karnovsky's fixative (glutaraldehyde and cacodylate buffer) before processing for electron microscopy by standard methods. The remainder of the specimen was placed in formalin and processed routinely for light microscopy. Electron micrographs of several magnifications were prepared and examined by one of us (I.C.T.). The morphological characteristics were noted and the smooth endoplastic reticulum was quantified by a modification of the method of Loud (1962). A grid, consisting of 11 parallel lines, spaced $15 \mathrm{~mm}$ apart and measuring $18 \times 22 \mathrm{~cm}$, was prepared. The grid was laid on 
photomicrographs of 20000 magnification taken randomly from blocks representing several regions of each biopsy. The number of intersections of the grid lines with the membrane profiles of the smooth endoplasmic reticulum was recorded as crossings per photomicrograph. For each biopsy photomicrographs from different areas of the hepatic lobule, including periportal and centrilobular regions, were thus examined, and the mean number of crossings of all the photomicrographs from each biopsy were recorded.

The percentage increment in serum bilirubin after 48 hours on a standard hospital diet of 400 calories
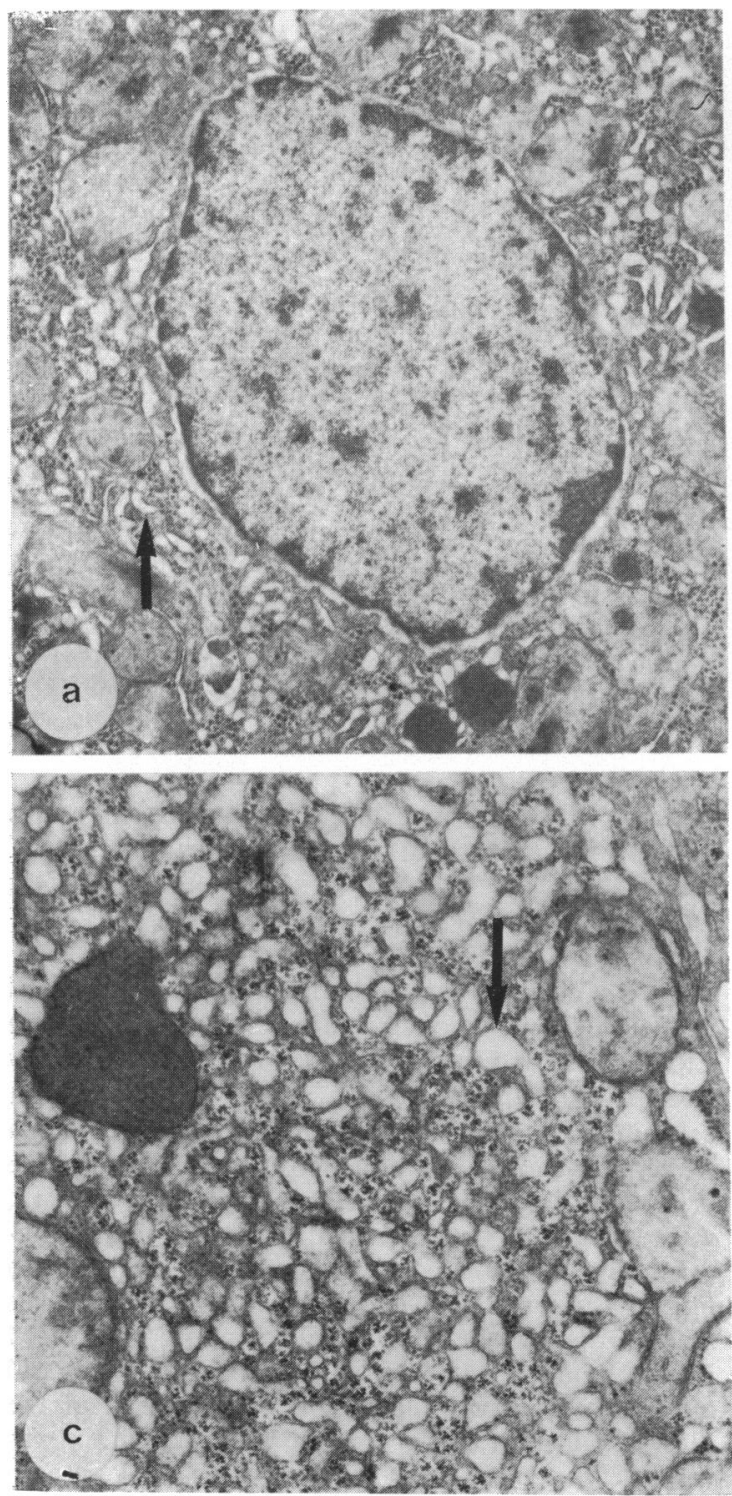

containing $11.5 \mathrm{~g}$ of fat was recorded for each patient. In addition, the bilirubin was measured at 30 minute intervals for up to 12 hours after intravenous injection of $50 \mathrm{mg}$ nicotinic acid and the percentage increment at 180 minutes was calculated. Red cell survival was determined by a standard chromium $^{51}$ red cell labelling technique (Dacie and Lewis, 1975) and the half-life calculated in days.

Two patients with known haemolysis (hereditary spherocytosis, mean serum bilirubin $66 \mu \mathrm{mol} / \mathrm{l}$ and G6PD deficiency, mean serum bilirubin $36 \mu \mathrm{mol} / \mathrm{l}$ ) were also studied by the above techniques. As controls, 12 healthy volunteers were subjected to

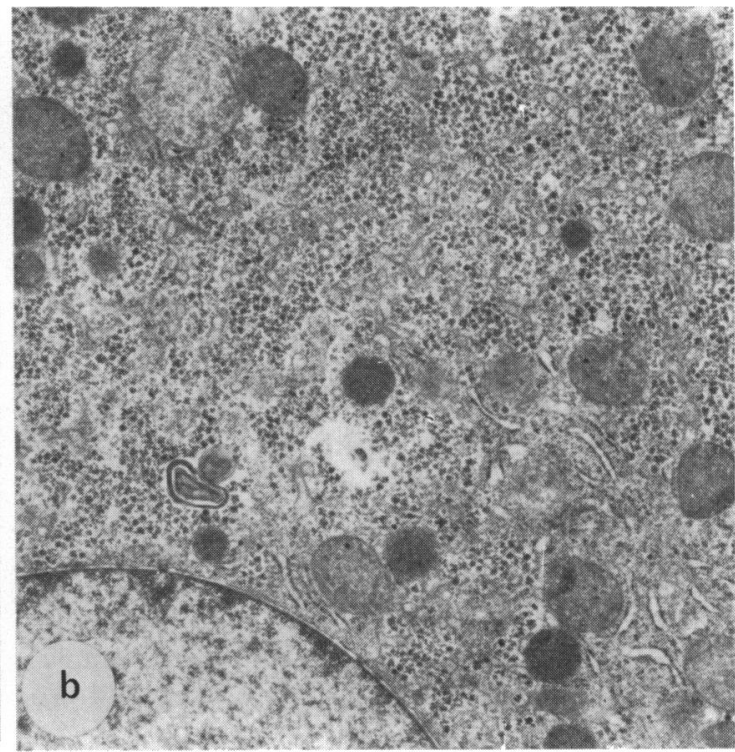

Fig 1. Electron micrographs of the hepatocytes from two patients with Gilbert's syndrome. (a) From a patient showing hypertrophy of the smooth endoplasmic reticulum. $x 12$ 600. Numerous hypertrophied vesicles of endoplasmic reticulum can be seen throughout the cytoplasm (arrow). (b) From a patient with normal appearances of the endoplasmic reticulum. $x 12$ 600. Much less smooth endoplasmic reticulum is evident. (c) From the same patient as in (a). High power views of cytoplasmic field showing hypertrophied smooth endoplasmic reticulum (arrow) 30000 . 
caloric restriction and nicotinic acid stimulation. Five control liver biopsies were obtained at negative laporatomy for chronic abdominal pain in patients shown subsequently to have no evidence of liver dysfunction. These studies were approved by the local ethics committees.

\section{Results}

\section{MORPHOLOGY}

Light microscopy of the liver biopsies showed no abnormalities. Lipofuscin pigment was noted in five biopsies. Electron microscopy, however, revealed two definite populations (Fig. 1). In 13 there was obvious gross hypertrophy of the smooth endoplasmic reticulum. These were designated Gilbert's EM Positive. The remaining 12 did not show this feature and were similar to normal controls. This group was designated Gilbert's EM Negative. These morphological differences were accompanied by marked quantitative differences in the smooth endoplasmic reticulum in the two groups (Fig. 2). There was no overlap between the two groups and the EM Positive group showed a significantly greater $(\mathrm{P}<0.001)$ mean number of crossings $(325 \pm 15 \mathrm{~m}$ mean \pm SEM) compared with the EM Negative group $(137 \pm 8)$, which did not differ from normal controls $(141 \pm 14)$. There were no other consistent abnormalities in either group. In particular, the plasma membrane and microvilli, mitochrondria, and Golgi apparatus were normal. Characteristic ultrastructural appearances of lipofuscin granules were seen in three of the EM Positive group and two

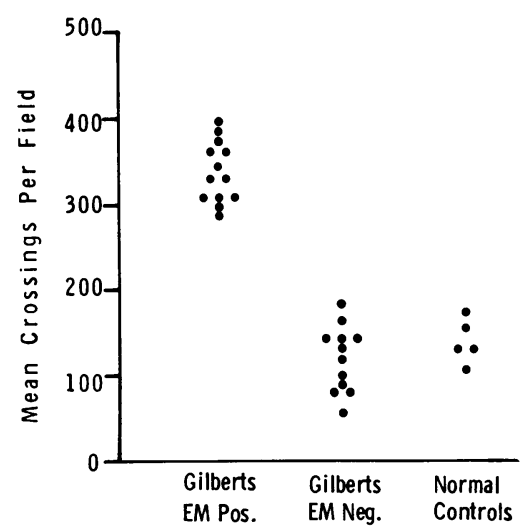

Fig. 2 Quantification of the smooth endoplasmic reticulum by grid technique. Number of crossings per field (mean for all photomicrographs from the different areas of each biopsy) in patients with Gilbert's syndrome and normal controls.

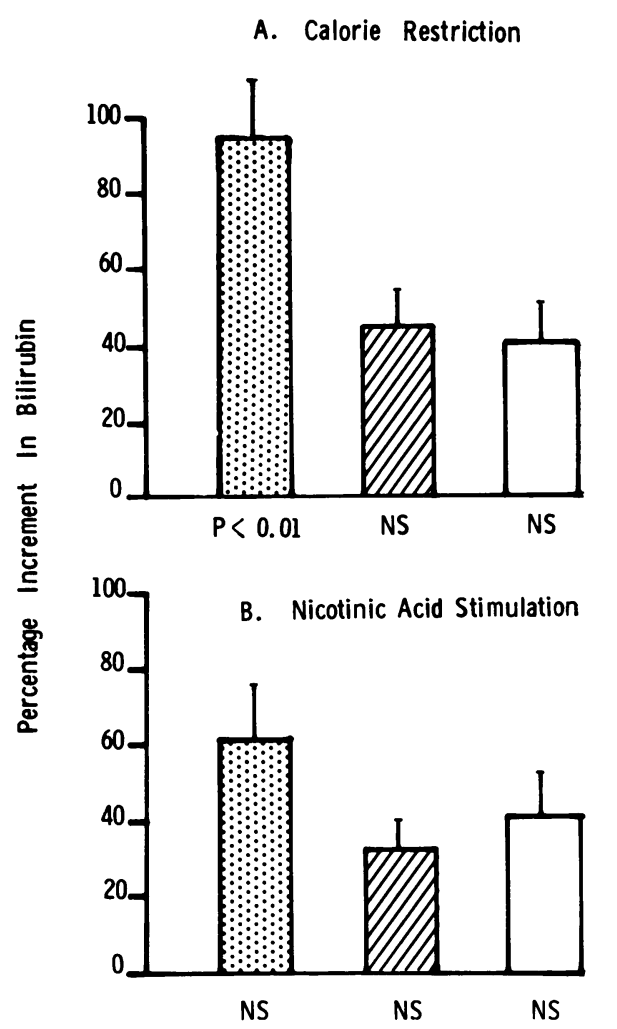

Fig. 3. Mean percentage increment in bilirubin in Gilbert's EM Positive and Gilbert's EM Negative patients compared with normal controls after (a) caloric restriction and $(b)$ nicotinic acid stimulation. Gilbert's EM Positive, $\square$ Gilbert's EM Negative, $\square$ Normal controls.

of the EM Negative group. The two patients with haemolysis had normal hepatic ultrastructure.

\section{CALORIC RESTRICTION AND NICOTINIC} ACID STIMULATION

The two groups, defined morphologically, differed in their response to caloric restriction (Fig. 3). In the EM Positive group there was a significantly greater $(P<0.01)$ mean percentage increase in bilirubin as compared with the normal controls. The mean percentage increase in bilirubin in the EM Negative group did not differ from normal controls. Overall, the response to nicotinic acid did not differ significantly in the Gilbert's patients when compared with normal subjects. However, a greater response was seen in the EM Positive group compared with EM Negative group and normal controls, but this did not reach statistical significance. The shape of the plasma bilirubin curve in response to bilirubin was variable but correlated best with the peak rise in 
bilirubin. Those patients with the greater percentage increase in bilirubin showed later peaks and delayed falls. The differences, as compared with the normal controls, were greatest at $\mathbf{1 8 0}$ minutes. The patients with haemolysis showed no appreciable rise in bilirubin on caloric restriction $(0 \%, 20 \%)$. After nicotinic acid injection, the patients with spherocytosis and G6PD deficiency showed $79 \%$ and $18 \%$ increments in bilirubin at $\mathbf{1 8 0}$ minutes respectively.

BILIRUBIN AND RED CELL SURVIVAL

The two electron microscopic groups did not differ in respect of age, sex, ethnic origin, clinical presentation, or mean basal serum bilirubin (Table). There was no difference in mean red cell survival, which was reduced in both groups compared with the 12 healthy control subjects. In the EM Positive group four patients had red cell half lives below our normally accepted lower limit of 27 days $(20,25$,

Table Bilirubin and red cell survival in two groups

\begin{tabular}{|c|c|c|c|}
\hline & Bilirubin & Red cell survival & \\
\hline & $($ molll; mean $\pm S E M)$ & (Days; mean $\pm S E M)$ & No. \\
\hline $\begin{array}{l}\text { EM Positive } \\
\text { EM Negative } \\
\text { Controls }\end{array}$ & $\begin{array}{l}34 \cdot 3 \pm 3 \cdot 3 \\
40 \cdot 2 \pm 7 \cdot 7 \\
10 \cdot 5 \pm 1 \cdot 3\end{array}$ & $\begin{array}{l}27 \cdot 0 \pm 1 \cdot 3 \\
26 \cdot 0 \pm 1 \cdot 4 \\
30 \cdot 5 \pm 1 \cdot 0\end{array}$ & $\begin{array}{l}13 \\
12 \\
12\end{array}$ \\
\hline
\end{tabular}

$25 \cdot 5,26 \cdot 3$ days). In the EM Negative group four patients also had reduced red cell half lives (18, $21 \cdot 5,24,25$ days).

\section{Discussion}

This study correlates the hepatic ultrastructural changes with response to caloric restriction and nicotinic acid stimulation in a series of 25 patients with Gilbert's syndrome. The patients were selected from consecutive referrals to centres not known for a special interest in liver disease and thus are probably a truly representative sample of patients with Gilbert's syndrome in the population as a whole. Quite characteristic gross hypertrophy of the smooth endoplasmic reticulum was seen in 13 of the 25 patients, in contrast with the 12 others who did not differ from normal controls. This separation into two groups was both obvious morphologically and confirmed by the quantification technique. Thus hypertrophy of the smooth endoplasmic reticulum is not a distinct characteristic of Gilbert's syndrome, as suggested by McGee et al. (1975), but is present in a substantial subpopulation. That this is a distinct rather than an artificial subpopulation is supported by the clear separation of the two groups by the quantification technique and the significantly greater bilirubin response to caloric restriction, with exaggerated response to nicotinic acid stimulation, in the EM Positive group. Furthermore, our results would explain the previously varied reports of endoplasmic reticulum abnormalities in Gilbert's syndrome in ultrastructural studies, on smaller groups of patients. Many authors found no abnormalities (Magnenat and Paluello, 1967; Feldmann et al., 1968; Barth et al., 1971), while others noted hypertrophy of the smooth endoplasmic reticulum as an inconstant feature (Novikoff and Essner, 1960; Simon and Varonier, 1963; Schaff et al., 1969; Blueger et al., 1977).

The reason for this hypertrophy and the differences between our two groups is not obvious. Similar hypertrophy of the smooth endoplasmic reticulum has been reported in rats when fasted (Fawcett, 1955; Porter and Bruni, 1959). There were, however, no differences in the nutritional status of our patients at the time of biopsy. Smooth endoplasmic reticulum hypertrophy also occurs in response to alcohol (Rubin et al., 1968) and enzyme-inducing drugs (Remmer and Merker, 1963). In this study we excluded all patients with excessive alcohol intakes and no patient had been receiving any therapy during the month before biopsy. That the appearances might, in a similar way, be induced by the bilirubin load is unlikely, as both our groups had similar mean red cell survivals and similar mean serum bilirubin levels, and hypertrophy was absent in our two patients with haemolytic disease. Hypertrophy of the smooth endoplasmic reticulum has been reported in Gunn rats (Novikoff and Essner, 1960) and the Crigler Najjar syndrome (Gollan et al., 1975). It is thus possible that the ultrastructural appearances are in some way related to the underlying biochemical defect (glucuronyl transferase deficiency), which is marked in these two situations. If this were so, then we would have to postulate that our two groups have different biochemical defects. This is certainly possible. There have been reports of subpopulations of patients with Gilbert's syndrome who, in addition to abnormalities of bilirubin metabolism, have abnormal handling of other organic anions, bromsulphthalein (Berk et al., 1972) and indocyanine green (Martin et al., 1976). Since indocyanine green does not require conjugation, this would require a second defect in addition to the glucuronyl transferase defect demonstrated by Black and Billing (1969). There have also been other reports of the heterogeneity of Gilbert's syndrome on the basis of bilirubin kinetic studies (Okolicsanyi et al., 1978) and studies of the conjugating enzymes (Auclair et al., 1976). It would thus be of interest to 
perform kinetic and enzyme studies on the two ultrastructual subpopulations to assess if the various subpopulations coincide, or whether they themselves are heterogeneous.

At the outset of the current study we considered that there might be some correlation between the endoplasmic reticulum abnormalities and the previously reported (Foulk et al., 1959; Powell et al., 1967; Berk et al., 1970) reduction in red cell survival in some patients with Gilbert's syndrome, perhaps reflecting a common membrane disorder. Our results, however, show the same number of patients in each group with diminished red cell half lives and a similar mean red cell half life in both groups. The overall numbers in our study with reduced red cell half lives $(32 \%)$ was similar to those reported by others. We conclude that the red cell disorder is an inconstant association which is unrelated to any hepatic ultrastructural features and which in itself is insufficient to explain the raised bilirubin.

The results of the provocation tests also lead us to question their diagnostic value in Gilbert's syndrome. Unlike Davidson et al. (1975), we found no significant differences from normal controls with the nicotinic acid stimulation test, which we also observed to cause unpleasant flushing in our patients and control subjects. The caloric restriction test was of value only if positive. Negative results occurred in both patients and controls. Although these negative responses conflict with previously reported series (Owens et al., 1973; Felsher et al., 1975), a positive response to caloric restriction has not been a universal experience in Gilbert's syndrome. Davidson et al. (1975) showed no significant rise overall in bilirubin on caloric restriction, with only four out of 13 patients showing appreciable rises. Barrett (1971) noted a rise in bilirubin in all his patients but this rise did not differ from the control group. Furthermore, in two of the 12 patients reported by Owens et al. there was no significant rise in bilirubin as compared with controls. Our present results underline this heterogeneity of response but do not shed further light on the mechanism. They do, however, suggest that the bilirubin response to caloric restriction is in some way associated with the proportion of smooth endoplasmic reticulum in the hepatocyte.

With the exception of the endoplasmic reticulum changes we found no other morphological or ultrastructural abnormalities in our patients with Gilbert's syndrome. We found no evidence of the abnormalities of the plasma membrane, microvilli, or mitochondria reported by several other authors (Simon and Varonier, 1963; Magnenat and Paluello, 1967; Feldmann et al., 1968; Schaff et al., 1969; Blueger et al., 1977).
We thank Professor F. Walker for his support and encouragement and Mrs R. Greensted for preparing the manuscript.

\section{References}

Arias, I. M. (1962). Chronic unconjugated hyperbilirubinemia without overt signs of hemolysis in adolescents and adults. Journal of Clinical Investigation, 41, 2233-2245.

Auclair, C., Hakim, J., Boivin, P., Troube, H., and Boucherot, J. (1976). Bilirubin and paranitrophenol glucuronyl transferase activities of the liver in patients with Gilbert's syndrome. An attempt at a biochemical breakdown of the Gilbert's syndrome. Enzyme, 21, 97-107.

Barrett, P. V. D. (1971). Hyperbilirubinemia of fasting. Journal of the American Medical Association, 217, 1349-1353.

Barth, R. F., Grimley, P. M., Berk, P. D., Bloomer, J. R., and Howe, R. B. (1971). Excess lipofuscin accumulation in constitutional hepatic dysfunction (Gilbert's syndrome) light and electron microscopic observations. Archives of Pathology, 91, 41-47.

Berk, P. D., Bloomer, J. R., Howe, R. B., and Berlin, N. I. (1970). Constitutional hepatic dysfunction (Gilbert's syndrome). A new definition based on kinetic studies with unconjugated radiobilirubin. American Journal of Medicine, 49, 296-305.

Berk, P. D., Blaschke, T. F., and Waggoner, J. G. (1972). Defective bromosulphthalein clearance in patients with constitutional hepatic dysfunction (Gilbert's syndrome). Gastroenterology, 63, 472-481.

Black, M., and Billing, B. H. (1969). Hepatic bilirubin UDP-glucuronyl transferase activity in liver disease and Gilbert's syndrome. New England Journal of Medicine, 280, 1266-1271.

Blueger, A. F., Krupnikova, E. Z., Sondore, V. Y., and Semushina, E. P. (1977). Study of the etiology and pathogenesis of low grade non-hemolytic unconjugated hyperbilirubinemia (Gilbert's disease). Acta HepatoGastroenterologica, 24, 140-147.

Dacie, J. V., and Lewis, S. M. (1975). Practical Haematology, p. 445-476. Churchill Livingstone: Edinburgh.

Davidson, A. R., Rojas-Bueno, A., Thompson, R. P. H., and Williams, R. (1975). Reduced caloric intake and nicotinic acid provocation tests in the diagnosis of Gilbert's syndrome. British Medical Journal, 2, 480.

Fawcett, D. W. (1955). Observations on the cytology and electron microscopy of hepatic cells. Journal of the National Cancer Institute, 15, 1475-1503.

Feldmann, G., Oudéa, P., Domart-Oudéa, M. C., Molas, G., and Fauvert, R. (1968). L'ultrastructure hépatique au cours de la maladie de Gilbert. Pathologie et Biologie, 16, 943-953.

Felsher, B. F., and Carpio, N. M. (1975). Caloric intake and unconjugated hyperbilirubinemia. Gastroenterology, 69, 42-47.

Foulk, W. T., Butt, H. R., Owen, C. A., Jr, Whitcomb, F. F., Jr, and Mason, H. L. (1959). Constitutional hepatic dysfunction (Gilbert's disease): its natural 
history and related syndromes. Medicine (Balt.), 38, 25-46.

Fromke, V. L., and Miller, D. (1972). Constitutional hepatic dysfunction (CHD; Gilbert's disease): a review with special reference to a characteristic increase and prolongation of the hyperbilirubinaemic response to nicotinic acid. Medicine (Balt.), 51, $451-464$

Gollan, J. L., Huang, S. N., Billing, B., and Sherlock, S. (1975). Prolonged survival in 3 brothers with severe type 2 Crigler-Najjar syndrome: ultrastructural and metabolic studies. Gastroenterology, 68, 1543-1555.

Levine, R. A., and Klatskin, G. (1964). Unconjugated hyperbilirubinemia in the absence of overt hemolysis: importance of acquired disease as an etiologic factor in 366 adolescent and adult subjects. American Journal of Medicine, 36, 541-552.

Loud, A. V. (1962). A method for the quantitative estimation of cytoplasmic structures. Journal of Cell Biology, 15, 481-487.

McGee, J. O'D., Allan, J. G., Russell, R. I., and Patrick, R. S. (1975). Liver ultrastructure in Gilbert's syndrome. Gut, 16, 220-224.

Magnenat, P., and Minio Paluello, F. (1967). Les ictères idiopathiques chroniques: étude ultrastructurale et remarques pathogéniques. Schweizerische Medizinische Wochenschrift, 97, 1102-1105.

Martin, J. F., Vierling, J. M., Wolkoff, A. W., Scharschmidt, B. F., Vergalla, J., Waggoner, J. G., and Berk, P. D. (1976). Abnormal hepatic transport of indocyanine green in Gilbert's syndrome. Gastroenterology, 70, 385-391.

Novikoff, A. B., and Essner, E. (1960). The liver cell: some new approaches to its study. American Journal of
Medicine, 29, 102-131.

Okolicsanyi, L., Ghidini, O., Orlando, R., Cortelazzo, S., Benedetti, G., Naccarato, R., and Manitto, P. (1978). An evaluation of bilirubin kinetics with respect to the diagnosis of Gilbert's syndrome. Clinical Science and Molecular Medicine, 54, 539-547.

Owens, D., and Sherlock, S. (1973). Diagnosis of Gilbert's syndrome. Role of reduced caloric intake test. British Medical Journal, 3, 559-563.

Porter, K. R., and Bruni, C. (1959). An electron microscope study of the early effects of $3^{1}$-Me-DAB on rat liver cells. Cancer Research, 19, 997-1009.

Powell, L. W., Billing, B. H., and Williams, H. S. (1967). An assessment of red cell survival in idiopathic unconjugated hyperbilirubinaemia (Gilbert's syndrome) by the use of radioactive di-isopropylfiuorophosphate and chromium. Australian Annals of Medicine, 16, 221225.

Remmer, H., and Merker, H. J. (1963). Drug-induced changes in the liver endoplasmic reticulum: association with drug metabolising enzymes. Science, 142, 16571658.

Rubin, E., Hutterer, F., and Lieber, C. S. (1968). Ethanol increases hepatic smooth endoplasmic reticulum and drug-metabolizing enzymes. Science, 159, 1469-1470.

Schaff, Z., Lapis, K., and Sáfrány, L. (1969). Feinstrukturelle Veränderungen der Leber bei der GilbertKrankheit (Ultrastructural changes of the liver in patients with liver disease). Beiträge zür Pathologischen Anatomie, 140, 54-70.

Simon, G., and Varonier, H. S. (1963) Étude au microscope électronique du foie de deux cas d'ictère non hémolytique congènital de type Gilbert. Schweizerische Medizinische Wochenschrift, 93, 459-465. 